3

4 Andreia Gomes ${ }^{1}$, Gustavo Correia ${ }^{1}$, Marisa Coelho ${ }^{1}$, João Ricardo Araújo ${ }^{1}$, Maria João

5 Pinho $^{2}$, Ana Luisa Teixeira ${ }^{3,4}$, Rui Medeiros ${ }^{3,4,5,6}$ and Laura Ribeiro ${ }^{1,7 *}$

6

$7 \quad{ }^{1}$ Department of Biochemistry, Faculty of Medicine, University of Porto, Alameda Prof.

8 Hernani Monteiro, 4200-319 Porto, Portugal

$9{ }^{2}$ Department of Pharmacology and Therapeutics, Faculty of Medicine, University of 10

\section{adrenal chromaffin cells}

Porto, Alameda Prof. Hernani Monteiro, 4200-319 Porto, Portugal

${ }^{3}$ Molecular Oncology Group, Portuguese Institute of Oncology of Porto, Rua Dr. António Bernardino de Almeida, 4200-072 Porto, Portugal

${ }^{4}$ ICBAS, Abel Salazar Institute for the Biomedical Sciences, University of Porto, Rua de Jorge Viterbo Ferreira n. ${ }^{\circ}$ 228, 4050-313 Porto, Portugal

${ }^{5}$ CEBIMED, Faculty of Health Sciences of Fernando Pessoa University, Praça 9 de Abril, $\mathrm{n}^{\circ}$ 349, 4249-004 Porto, Portugal

${ }^{6}$ LPCC, Research Department-Portuguese League Against Cancer (Núcleo Regional do Norte), Estrada Interior da Circunvalação, nº 6657, 4200- 177 Porto, Portugal

${ }^{7}$ Department of Medical Education and Simulation, Faculty of Medicine,University of Porto, Alameda Prof. Hernani Monteiro, 4200-319 Porto, Portugal

*Corresponding author. Department Biochemistry, Faculty of Medicine, University of Porto, Alameda Prof. Hernani Monteiro, 4200-319, Porto, Portugal. Tel./fax: +351 22 5513624. E-mail address: lribeiro@med.up.pt

Running title: Dietary fatty acids and catecholamine handling

Andreia Gomes and Gustavo Correia equally contributed to the work 
30 Abbreviations: AA, arachidonic acid; AD, adrenaline; CA, catecholamines; COMT, 31 catechol-O - methyltransferase; CDV, cardiovascular; DHA, docosahexaenoic acid; EA, 32 elaidic acid; EP3R, prostaglandin E3 receptor; EPA, eicosapentaenoic acid; FA, fatty 33 acids; GAPDH, glyceraldehyde-3-phosphate dehydrogenase; $\mathrm{KCl}$, potassium chloride; 34 LA, linoleic acid; MAO, monoamine oxidase; MTT, 3-(4,5-dimethylthiazol-2-yl)-2,535 diphenyl tetrazolium bromide; NA, noradrenaline; NET, noradrenaline transporter; OA, 36 oleic acid; PGE2, prostaglandin E2; PNMT, phenylethanolamine N-methyltransferase; $37 \mathrm{TH}$, tyrosine hydroxylase; VMAT, vesicular monoamine transporter; $\gamma$-LIN, $\gamma$-linolenic 38 acid. 


\section{Abstract}

42

Catecholamines (CA) play an important role in cardiovascular (CDV) disease risk. Namely, noradrenaline (NA) levels positively correlate whereas adrenaline (AD) levels negatively correlate with obesity and/or CDV disease. Western diets, which are tipically rich in $\Omega-6$ fatty acids (FA) and deficient in $\Omega-3$ FA, may contribute to the development of obesity, type 2 diabetes and/or coronary artery disease. Taking this into consideration, and the fact that our group has already described that saturated FA affect catecholamine handling by adrenal chromaffin cells, this work aimed to investigate the effect of unsaturated FA upon catecholamine handling in the same model. Our results showed that chronic exposure to unsaturated FA differently modulated CA cellular content and release, regardless of both FA serie and number of carbon atoms. Namely, the $\Omega-6$ arachidonic and linoleic acids, based on their effect on CA release and cellular content, seemed to impair NA and AD vesicular transport, whereas $\gamma$-linolenic acid selectively impaired AD synthesis and release. Within the $\Omega-9$ FA, oleic acid was devoid of effect and elaidic acid behaved similarly to $\gamma$-linolenic acid. Eicosapentaenoic and docosahexaenoic acids ( $\Omega$-3series) impaired the synthesis and release of both NA and AD. These results deserve attention and future development, namely in what concerns the mechanisms involved and correlative effects in vivo.

Key-words: Noradrenaline, adrenaline, unsaturated lipids, tyrosine hydroxylase, phenylethanolamine N-methyltransferase

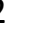




\section{Introduction}

Obesity prevalence is dramatically increasing worldwide, being associated with an increased risk of cardiovascular (CDV) and metabolic disorders [1]. Adrenaline (AD) and noradrenaline (NA), the main catecholamines (CA) secreted by the sympathoadrenomedullary system, play a crucial role in the regulation of metabolic and CDV homeostasis. The release of AD and NA into the circulation is controlled by a wide range of factors both in normal and stress conditions [2, 3]. Interestingly, plasma NA positively correlates with obesity and CDV risk, whereas AD levels show an inverse association with CDV mortality $[4,5]$. Moreover, in humans, CA are important regulators of adipose tissue lipolysis, having a lipolytic effect by acting on $\beta$-adrenergic receptors or an anti-lipolytic effect by acting on $\alpha 2$-adrenergic receptors [6].

Fatty acids (FA) act as important metabolic substrates and components of biological membranes. However, they also function as signaling molecules, regulating a wide range of physiological responses [7], such as gene transcription and metabolic and inflammatory responses [8]. Typical western diets are normally rich in $\Omega-6$ and trans FA (non-essential FA used as substitutes for saturated FA in diet [9]) and deficient in $\Omega$ 3 FA being the ratio of $\Omega-6$ to $\Omega-3$ generally $>10: 1$, whereas on a primitive human diet it was closer to 1:1 [10]. An elevated consumption of saturated and trans FA over mono and polyunsaturated FA or a dysfunction in their metabolism contributes to the development of many chronic diseases such as obesity, type 2 diabetes, cancer [7] and psychological disturbances [11]. This could be related with the fact $\Omega-3$ FA are usually associated with cardioprotective benefits due to their multiple physiological effects on lipids, blood pressure, vascular function, cardiac rhythms, platelet function, and inflammatory responses [12]. Indeed, epidemiological, human and animal studies suggest that a $\Omega-3$ rich diet may decrease the risk factors for metabolic syndrome including hyperglycemia, insulin resistance, hypertension, dyslipidemia and central adiposity [13]. In line with this, a recent report showed that $\Omega-3$ FA are able to increase sympathetic activation and reduce abdominal adiposity [14].

In addition, consumption of trans FA raises the levels of low-density lipoproteins and triglycerides, lowers the levels of high-density lipoproteins, induces an inflammatory response, and, even at low levels of intake, significantly increases the risk of coronary events $[8,15]$.

Although both in vitro [16-18] and in vivo [19] studies reported that FA can have profound effects on neurosecretion, very limited information is available concerning the 
107 effect of these molecules on CA handling by adrenal chromaffin cells [20, 21]. So, in 108 the present work, we investigated the effect of several unsaturated fatty acids on CA 109 synthesis and secretion in adrenal chromaffin cells. For that purpose, the effect of 110 chronic exposure to monounsaturated, polyunsaturated and trans fatty acids on CA 111 cellular content and release was investigated, using bovine adrenal chromaffin cells. 112 Additionally, the effects of these FA on the expression of tyrosine hydroxylase (TH), 113 the rate-limiting enzyme of the CA synthesis, and phenylethanolamine $\mathrm{N}$ 114 methyltransferase (PNMT), the enzyme that converts NA to AD, were also evaluated. 


\section{Materials and methods}

117

118

119

120

121

122

123

124

125

126

127

128

129

130

131

132

133

134

135

136

137

138

139

140

141

142

143

144

145

146

147

148

149

\subsection{Materials}

Eicosapentaenoic acid (EPA), docosahexaenoic acid (DHA), linoleic acid (LA), $\gamma$-linolenic acid ( $\gamma$-LIN), arachidonic acid (AA), oleic acid (OA), elaidic acid (EA), MTT (Methylthiazolyldiphenyl-tetrazolium bromide), Dulbecco's Modified Eagle's medium/F12, octenylsuccinic anhydride (OSA), Tris (tris-(hydroxymethyl)aminomethane hydrochloride), fetal calf serum, L-glutamine, HEPES, cytosine arabinoside, penicillin, streptomycin, amphotericin B, inhibitor of RNAses, pargyline, perchloric acid, collagenase A, ascorbic acid (Sigma, St. Louis, MO, USA); albumin, EDTA, Titron X-100, methanol, citric acid, D (+) glucose (Merck, Darmstadt, Germany); SuperScript ${ }^{\mathrm{TM}}$ II Reverse Transcriptase, RNAse H, GAPDH, SYBR Green I detection, chloroform (Invitrogen, Life Technologies, Grand Island, NY, USA); Tripure isolation reagent (Roche Diagnostics, Mannheim, Germany).

\subsection{Preparation of adrenal medullary cells}

Bovine adrenal glands were obtained from a local slaughterhouse and were processed for cell culture within 2 hours of slaughter, being transported to the laboratory in ice-cold $\mathrm{Ca}^{2+}-\mathrm{Mg}^{2+}$-free buffer (containing: $154 \mathrm{mM} \mathrm{NaCl}, 2.6 \mathrm{mM} \mathrm{KCl}, 0.85 \mathrm{mM}$ $\mathrm{KH}_{2} \mathrm{PO}_{4}, 2.15 \mathrm{mM} \mathrm{K} \mathrm{HPO}_{4}, 10 \mathrm{mM}$ glucose and $12.7 \mathrm{mM}$ HEPES, pH 7.4). The chromaffin cells were isolated by digestion with collagenase A as described by Livett et al. $[22,23]$ with some modifications. Briefly, the adrenal glands were trimmed of fat and washed with $\mathrm{Ca}^{2+}-\mathrm{Mg}^{2+}$-free buffer. The buffer was injected into the adrenal vein in order to wash the remaining blood from the gland. The adrenal glands were digested with a $\mathrm{Ca}^{2+}-\mathrm{Mg}^{2+}$-free buffer containing $0.25 \%$ collagenase A and $0.01 \%$ DNAse I. Five $\mathrm{mL}$ of this solution was injected into the adrenal vein of each gland. This procedure was repeated every $15 \mathrm{~min}$ with the glands incubated at $37{ }^{\circ} \mathrm{C}$ in $\mathrm{Ca}^{2+}-\mathrm{Mg}^{2+}$ free buffer. After $45 \mathrm{~min}$, the digested medullary tissue was mechanically separated from the adrenal cortex and incubated in buffer, containing collagenase $\mathrm{A}$, for $30 \mathrm{~min}$ at $37{ }^{\circ} \mathrm{C}$. Subsequently, cells were filtered through a $200 \mu \mathrm{m}$ nylon mesh. Afterwards, filtered cells were centrifuged $3 \times$ at $1000 \mathrm{~g}$ for $3 \mathrm{~min}$ and washed with $\mathrm{Ca}^{2+}-\mathrm{Mg}^{2+}$-free buffer in order to remove the collagenase A/DNAse. At last, they were filtered through a $100 \mu$ m nylon mesh. 


\subsection{Cell culture}

Bovine chromaffin cells were cultured in Dulbecco's Modified Eagle's medium (nutrient mixture F-12 Ham (1:1), supplemented with 10\% fetal calf serum, 2 mM Lglutamine, $15 \mathrm{mM}$ HEPES, $10 \mu \mathrm{M}$ cytosine arabinoside, 100 units/mL penicillin, 100 $\mathrm{mg} / \mathrm{mL}$ streptomycin and $0.25 \mu \mathrm{m} / \mathrm{mL}$ amphotericin B). The dispersed cells were plated in collagen-coated 24-well plastic culture dishes $\left(2 \mathrm{~cm}^{2} ; \varnothing 15.6 \mathrm{~mm}\right)$ at a density of 4-5 x $10^{5}-10^{6}$ cells/well and incubated at $37{ }^{\circ} \mathrm{C}$ in an atmosphere consisting of $5 \% \mathrm{CO}_{2}$ in air and with $99 \%$ of relative humidity. Culture medium was replaced every 24 hours and, for the experiments, cells were used after 4 days in culture. Twenty-four hours before experiment, the bovine chromaffin cells were cultured in fetal calf serum-free medium [3].

\subsection{In vitro experiments}

\subsubsection{Chronic treatment with fatty acids}

After 4 days in culture, and before the studies on CA handling, cells were incubated for 24 hours (chronic exposure) with ethanol or DMSO (controls), linoleic acid (18:2n-6), $\gamma$-linolenic acid (18:3n-6), docosahexaenoic acid (22:6n-3), eicosapentaenoic acid (20:5n-3) arachidonic acid (20:4n-6), oleic acid (18:1n-9, cis) or elaidic acid (18:1n-9, trans). The concentrations of the tested FA (50 and $100 \mu \mathrm{M})$ are considered to be within the physiological range [24] all the fatty acids were dissolved in ethanol with the exception of oleic acid, which was dissolved in DMSO (0.1\% (v/v)).

\subsubsection{Studies on CA handling}

The experiments were performed in buffer solution with the following composition: $125 \mathrm{mM} \mathrm{NaCl}, 4.8 \mathrm{mM} \mathrm{KCl}, 1.2 \mathrm{mM} \mathrm{MgSO}_{4}, 1.2 \mathrm{mM} \mathrm{KH}_{2} \mathrm{PO}_{4}, 1.2 \mathrm{mM}$ $\mathrm{CaCl}_{2}, 25 \mathrm{mM}$ HEPES-NaOH, $5.6 \mathrm{mM} \mathrm{D(+)} \mathrm{glucose,} 1 \mathrm{mM}$ ascorbic acid, $0.1 \mathrm{mM}$ pargyline and $0.01 \mathrm{mM}$ tolcapone, $\mathrm{pH}$ 7.4. After the chronic treatment with the several fatty acids, cells were pre-incubated for $10 \mathrm{~min}$, at $37^{\circ} \mathrm{C}$, in order to study basal release. Initially, the culture medium was removed and cells were washed with buffer at $37{ }^{\circ} \mathrm{C}$. Afterwards, cells were incubated for $15 \mathrm{~min}$ in the absence (control) or presence of potassium chloride $(\mathrm{KCl})(50 \mathrm{mM})$. Incubation was stopped by rinsing the cells with ice-cold medium $\left(4^{\circ} \mathrm{C}\right)$. Cells were solubilized with $0.3 \mathrm{~mL}$ 
$0.1 \%(\mathrm{v} / \mathrm{v})$ Triton X-100 (in $5 \mathrm{mM}$ Tris.HCl, $\mathrm{pH} 7.4)$ or perchloric acid (0.2 M) for the determination of proteins or $\mathrm{CA}$, respectively, and placed at $37^{\circ} \mathrm{C}$ overnight.

\subsubsection{Determination of catecholamines levels}

CA cellular content and release were determined by high pressure liquid chromatography with electrochemical detection (HPLC-ED) using the methodology described by Soares-da-Silva et al. [25]. The lower limits of CA detection varied from 350 to $1000 \mathrm{fmol}$.

\subsubsection{Enzymatic expression by quantitative real-time PCR}

Total RNA was extracted with Tripure $^{\circledR}$ isolation reagent (Roche Applied Science, Switzerland), according to manufacturer's instructions. For cDNA synthesis, 5 $\mu \mathrm{g}$ of total RNA was incubated at $45^{\circ} \mathrm{C}$ for 1 hour in a total volume of $20 \mu \mathrm{L}$ with 200 $\mathrm{U} / \mu \mathrm{L}$ of Superscript ${ }^{\mathrm{TM}}$ II Reverse Transcriptase, in $50 \mathrm{ng} / \mu \mathrm{L}$ random hexamers, 10 $\mathrm{mmol} / \mathrm{L}$ per dNTP, $15 \mathrm{mM} \mathrm{MgCl}, 375 \mathrm{mM} \mathrm{KCl}, 250 \mathrm{mM}$ Tris-HCl, pH 8.3 (at room temperature), $40 \mathrm{U} / \mu \mathrm{L}$ RNase inhibitor (RNaseOUT ${ }^{\mathrm{TM}}$ ). Reverse Transcriptase II was included, incubating at $25^{\circ} \mathrm{C}$ during $10 \mathrm{~min}$, followed by $50 \mathrm{~min}$ at $42^{\circ} \mathrm{C}$ and $70^{\circ} \mathrm{C}$ for $15 \mathrm{~min}$. Samples were incubated with $1 \mu \mathrm{L}$ RNAse $\mathrm{H}$ for $20 \mathrm{~min}$ at $37^{\circ} \mathrm{C}$. After cDNA synthesis, TH and PNMT mRNA expression levels were analyzed by relative quantification using quantitative real-time PCR (qRT-PCR) with SYBR Green I detection. The qRT-PCR was performed in a StepOne ${ }^{\mathrm{TM}}$ qPCR machine (Applied Biosystems, Foster City, CA, USA) and glyceraldehyde-3-phosphate dehydrogenase (GAPDH) was used as the housekeeping gene. The default thermocycler conditions have been used for all genes: 10 min of pre-incubation at $95^{\circ} \mathrm{C}$ followed by 40 cycles for 15 seconds at $95^{\circ} \mathrm{C}$ and $1 \mathrm{~min}$ at $60^{\circ} \mathrm{C}$. Following amplification, melting curve analyses verify the authenticity of the amplified products by their specific melting temperatures (Tm) according to the instructions of the manufacturer. The quantification reactions were carried out in $20 \mu \mathrm{L}$ volumes in a 48 -well plate (Applied Biossystems ${ }^{\mathrm{TM}}$ ) containing $300 \mathrm{nM}$ of forward and reverse primers, 1X FastStart universal SYBR green master (ROX) (Roche Applied Science, Switzerland) and approximately $5 \mu \mathrm{L}$ of cDNA. The following primers for bovine TH, bovine PNMT and GAPDH were used: 5'- ATC ATG TCC CCA CGC TTC GTC-3' (forward primer bovine TH), 5'- GCC TTC CCG TCC CTC TCC AC-3' (reverse primer bovine TH), 5'- CTA CCT CCG CAA CAA CTA CGC-3' (forward primer bovine PNMT), 5'- TGT CCT CAA AGT GGG CAC 
AG-3' (reverse primer bovine PNMT), 5' -CGA CAC TCA CTC TTC TAC CTT-3' (forward primer GAPDH), 5'-GTC CAC CAC CCT GTT GCT GTA-3' (reverse primer GAPDH). The data analysis was carried out using the StepOne ${ }^{\text {TM }}$ Software version 2.2 (Applied Biosystems, Foster City, CA, USA) with the same baseline and threshold set for each plate, in order to generate threshold cycle $(\mathrm{Ct})$ values for both genes in each sample.

\subsubsection{Cellular viability}

Cellular viability, after chronic treatment with the FA, was assessed by MTT [3(4,5-dimethylthiazol-2-yl)-2,5-diphenyl tetrazolium bromide] method. MTT method is based on the activity of a mitochondrial dehydrogenase which cleaves a yellow dye (MTT), forming purpur crystals of formazan and this reaction occurs only in viable cells. The amount of product formed was determined spectrophotometrically [26].

\subsubsection{Protein quantification}

Protein concentration was determined as described by Bradford [27], using human serum albumin as standard.

\subsection{Statistical analysis}

The release of $\mathrm{CA}$ into the medium was calculated during periods $\mathrm{A}$ and $\mathrm{B}$, corresponding to the first $10 \mathrm{~min}$ and to the following $15 \mathrm{~min}$ incubation periods, respectively. Release of CA from bovine adrenal chromaffin cells into the incubation medium during periods A or B was expressed as total, which corresponds to the amount of $\mathrm{CA}$ released into the medium in relation to the total cellular content of $\mathrm{CA}$ at the beginning of the release period. Basal and $\mathrm{KCl}$-stimulated release correspond to release periods $\mathrm{A}$ and $\mathrm{B}$, respectively.

Results were expressed in median (p25 - p75). Data were analyzed using IBM SPSS statistics 21 software.

Normal distribution of data was tested by Shapiro-Wilk test. The groups, of each category, were compared using one-way ANOVA (group and time) test for parametric data and Kruskal-Wallis test for non-parametric data. The homogeneity of variance was tested using Levene's test. Regarding qRT-PCR, data analysis was carried out using the computer software SPSS for Windows (version 19). The relative expression was determined using the $2^{-\Delta \Delta \mathrm{Ct}}$ method [28], and expression values were normalized to 
251 GAPDH. The $2^{-\Delta \Delta \mathrm{Ct}}$ method, along with Student's t-test or Mann-Whitney $U$ test, were 252 used in order to evaluate statistical differences in the normalized expression of the 253 targets analyzed among the different experimental conditions tested. The $P$ value 254 obtained was considered statistically significant under 0.05 .

255 


\section{Results}

In order to assess whether unsaturated fatty acids alter CA handling by bovine chromaffin cells, these cells were submitted to mono-, trans- and polyunsaturated fatty acids exposure for 24 hours, and the following parameters were evaluated: CA total and cellular content (both basal and $\mathrm{KCl}$-stimulated release) and mRNA levels of TH and PNMT.

Under control conditions, the median cellular content at the end of the experiments was found to be $604 \pm 33$ and $228 \pm 21 \mathrm{nmol} / \mathrm{mg}$ protein for AD and NA, respectively. Basal release during $10 \mathrm{~min}$ of pre-incubation, was $0.015 \pm 0.001$ and $0.0145 \pm 0.001$ for $\mathrm{AD}$ and NA, respectively. The release of AD and NA was increased by excess $\mathrm{KCl}$ to about $3.31 \pm 0.25$ and $2.95 \pm 0.36$ of control, respectively.

\subsection{Catecholamine total content}

Regarding CA total content (which includes cellular plus released contents), we observed that LA and DHA, in both concentrations (50 and $100 \mu \mathrm{M}$ ), were able to significantly decrease the content of both CA (tables 1 and 2). For the highest concentration, AD total content achieved after LA and DHA treatments was 220.76 $(195.78-334.53) \mathrm{nmol} / \mathrm{mg}$ protein and 5594.61 (5252.21 - 6205.32) $\mathrm{nmol} / \mathrm{mg}$ protein, respectively, and for NA the total content was $114.65(102.74-164.39) \mathrm{nmol} / \mathrm{mg}$ protein and $1183.82(533.52$ - 1336.95) nmol/mg protein, respectively. We observed that EA and $\gamma$-LIN significantly decreased the content of both AD and NA, when used at the highest concentration $(100 \mu \mathrm{M})$. On the contrary, EPA, OA and AA did not significantly affect total content of both CA (tables 1 and 2).

None of the FA tested altered bovine chromaffin cells viability (results not shown).

\subsection{Catecholamine cellular content}

In agreement with what was observed for CA total content, LA diminished the cellular content of both CA in a concentration-dependent way. LA at 50 and $100 \mu \mathrm{M}$ was capable of reducing NA cellular content to about $73 \%$ and $12 \%$, respectively, in comparison with controls (table 1). For AD cellular content, LA at 50 and $100 \mu \mathrm{M}$ reduced it approximately $79 \%$ and $11 \%$ respectively, in comparison with controls (table 2). On the other hand, both EA and $\gamma$-LIN significantly decreased the content of both 
$289 \mathrm{AD}$ and NA, but only at the highest concentration tested $(100 \mu \mathrm{M})$. In contrast, EPA, 290 DHA, OA and AA did not significantly modify CA cellular content (tables 1 and 2).

291

292

293

294

295

296

297

298

299

300

301

302

303

304

305

306

307

308

309

310

311

312

313

314

315

316

317

318

\subsection{Catecholamine basal release}

In relation to basal release, AA, LA and EA did not differentiate between $\mathrm{AD}$ and NA, but had opposite effects over both CA: AA significantly augmented their basal release in the same degree (to about $159 \%$ for both CA), whereas EA and LA inhibited the release of these amines. On the other hand, the chronic exposure to OA, DHA, EPA and $\gamma$-LIN did not change the basal release of both CA (tables 1 and 2).

\subsection{Catecholamine KCl-stimulated release}

In a concentration independent manner, EPA, DHA, EA and AA were able to significantly decrease the release of both $\mathrm{CA}$ induced by $\mathrm{KCl}$ at both concentrations (tables 1 and 2). In addition, $\gamma$-LIN was able to diminish the release of NA induced by $\mathrm{KCl}$ at both concentration however, this $\mathrm{FA}$ decreased $\mathrm{AD}$ release only when tested at $100 \mu \mathrm{M}$ (table 2). OA decreased the release of both CA to about $58 \%$ and $65 \%$ (for AD and NA, respectively) in comparison with the release induced by $\mathrm{KCl}$, but only for the highest concentration tested (tables 1 and 2). On the other hand, LA was the only fatty acid capable of significantly augmenting the $\mathrm{KCl}$-stimulated release of $\mathrm{AD}$ to about $145 \%$, but only at $100 \mu \mathrm{M}$ (table 2).

\subsection{TH and PNMT mRNA levels}

In order to evaluate the mRNA expression of both TH and PNMT we performed qRT-PCR. As seen in Fig. 1, only EPA was capable of significantly changing the mRNA expression of TH, by decreasing its levels. As shown in Fig. 2, LA, EA, EPA, $\gamma$ LIN and DHA significantly decreased the expression of PNMT, DHA being the most effective in this reduction $(\mathrm{p}<0.001, \mathrm{p}=0.003, \mathrm{p}=0.031, \mathrm{p}=0.011$ and $\mathrm{p}=0.001$, respectively for LA, EA, EPA, $\gamma$-LIN and DHA). However, neither AA (data not shown) nor OA significantly changed the expression of these enzymes. 


\section{Discussion}

The aim of this work was to study the effect of unsaturated FA on CA handling by bovine adrenal chromaffin cells. In general, our results showed that several unsaturated FA affected AD and NA handling through distinct ways, regardless of both the number of carbons (chain length) and double bonds. The FA tested altered four different parameters: CA synthesis and accumulation, CA basal release and CA release in response to depolarization by $\mathrm{KCl}$ (Fig. 3). In relation to the synthesis and accumulation of CA, fatty acids showed distinct behaviors: 1) EA, LA and $\gamma$-LIN decreased both the synthesis and accumulation of CA; 2) DHA and EPA decreased the synthesis but maintained the accumulation of $\mathrm{CA}$; 3) OA and AA did not change either the synthesis or the accumulation of CA. Moreover, EA, LA and $\gamma$-LIN affected the production of AD by decreasing PNMT mRNA levels (Fig. 3 A-1 and B-1). In contrast, EPA may affect the synthesis of CA since it was able to decrease the mRNA levels of TH and PNMT, but curiously preserved their total and cellular content. Concerning DHA, it did not affect CA accumulation since it maintained the cellular content of both $\mathrm{CA}$, but decreased the production of AD by interfering with PNMT levels. OA and AA did not affect either the expression of any of the enzymes or the content of CA.

Similarly to what happened with the synthesis and accumulation of CA, FA were able to differentially affect $\mathrm{CA}$ basal release. Among all, only AA was able to increase the basal release of both CA, whereas LA and EA decreased it for both CA. Curiously, LIN, EPA and DHA did not affect this release. At last, all fatty acids, with the exception of LA, were able to decrease the release of both CA induced by depolarization with $\mathrm{KCl}$, whereas LA increased this parameter.

The consumption of trans FA has been associated with a higher risk of coronary heart disease, insulin resistance, sudden death and impaired early development [29-32]. Some of the mechanisms through which trans fatty acids contribute to this higher risk have already been described. In fact, several works showed that they increase plasmatic levels of low-density lipoproteins, triglycerides, apolipoprotein $\mathrm{B}$ and $\mathrm{C}$ reactive protein, decrease plasmatic levels of high-density lipoproteins and interfere with enzymes involved in fatty acids metabolism [30, 31, 33]. Trans fatty acids are present in variable quantities in a broad range of foods, and despite legislative intervention and health initiatives, dietary FA remain a concern, owing to the addition of industrially produced trans fat to foods and the excessive reheating of frying oils [34]. Due to this, the study of trans FA cellular effects on CA metabolism is of major importance. Our 
353 work describes for first time the effect of trans FA upon CA handling by chromaffin cells. In our study, EA, the OA trans isomer, and the most representative in foods (8090\% of total trans), decreased all the parameters studied for NA and AD in the studied cells, except for TH expression. Given that other authors have shown that EA does not affect $\mathrm{Ca}^{2+}$-induced CA secretion in these cells [35], the decrease in both CA release was probably a consequence of a lower cellular content. Regarding PNMT mRNA levels, the ability of EA to alter its gene expression was already described in other cellular models [31], whereas the lack of effect over TH is somehow in accordance with its inability to activate this enzyme [35]. In fact, the decrease of PNMT expression could explain the reduction of AD content. Although EA did not alter TH expression, it could eventually decrease its function, leading to a reduction of both NA content and release.

Chromaffin cells exposure to AA suggests that this FA affected vesicular monoamine transporter (VMAT) function, since it was able to increase the basal release of $\mathrm{CA}$, decrease their release after depolarization with $\mathrm{KCl}$ and sustain cellular and total CA content (a reserpine-like effect) and PNMT and TH expression. In fact, the inhibition of VMAT (Fig. 3, C-1), a reserpine-like effect, could explain the increase of CA basal release associated with a lower accumulation of these amines in granules, suggested by a lower response after $\mathrm{KCl}$ stimulation. On the contrary, in bovine chromaffin cells, it was already described that melittin (a known activator of phospholipase $\mathrm{A}_{2}\left(\mathrm{PLA}_{2}\right)$ [36], which synthesizes AA) stimulates CA secretion in a $\mathrm{Ca}^{2+}$-dependent way [37]. It was also shown that $\mathrm{PLA}_{2}$ coupled to pertussis toxinsensitive G-protein can be a crucial element for the late $\mathrm{Ca}^{2+}$-dependent stage of exocytosis in these cells [38]. This could suggest that AA may modulate CA exocytosis, since this FA and/or its metabolites are able to affect intracellular $\mathrm{Ca}^{2+}$ levels through either activation of $\mathrm{Ca}^{2+}$ channels [39] and mobilization from intracellular stores [40].

Since it was already described that chromaffin cells express cyclooxygenase [4143], we cannot exclude that the observed effects could also be mediated by prostaglandins originated from AA after cyclooxygenase action. In fact, chromaffin cells express prostaglandin receptors [44-46] and, after binding to prostaglandin E3 receptor (EP3R), prostaglandin E2 (PGE2) causes a decrease in intracellular $\mathrm{Ca}^{2+}$ levels via pertussis toxin sensitive $G$ proteins and/or insensitive $G$ proteins $[47,48]$. The above effects are somehow in accordance with our own results since AA, probably through its 
387 conversion to PGE2, was able to decrease CA release after depolarization by $\mathrm{KCl}$ (Fig. 388 3. C-2).

In partial agreement to what was described for AA, our results suggest that $\gamma-$ LIN seems to decrease VMAT function since this FA was able to maintain CA basal release and decrease $\mathrm{KCl}$-stimulated CA release. However, in contrast to AA, $\gamma$-LIN did not decrease CA basal release once there was a reduction of their content. This could be explained by the decrease of PNMT expression and impairment of TH function. Even activity and leading to diminished NA content. On the other hand, some studies showed that $\gamma$-LIN can be converted into dihomo-gama-linolenic acid and AA, the precursors for PGE1 and PGE2, respectively [49]. Therefore, the conversion of $\gamma$-LIN into AA could result in a reduction of intracellular $\mathrm{Ca}^{2+}$ levels, through the activation of EP3R by PGE, leading to a decrease of CA KCl-stimulated release.

Another $\Omega-6$ FA, LA, increased the $\mathrm{KCl}$-stimulated release of $\mathrm{AD}$, and decreased both CA basal release and both total and cellular content. The ability of LA to increase the $\mathrm{AD}$ release after depolarization by $\mathrm{KCl}$ might be related with either an increase of the expression and/or activity of VMAT (Fig. 3. B-2) or an increase of intracellular $\mathrm{Ca}^{2+}$ levels (Fig. 3. B-3). The rise of VMAT function can lead to a larger $\mathrm{AD}$ accumulation into chromaffin granules, which could be translated into a decrease of $\mathrm{AD}$ in cytosol, diminishing both $\mathrm{CA}$ content and basal release. On the other hand, several studies, in different cells types, have shown that LA has the ability to increase intracellular $\mathrm{Ca}^{2+}$ levels through a mechanism dependent on inositol trisphosphate [50, 51] and extracellular $\mathrm{Ca}^{2+}$ influx [50]. Interestingly, in mice gustatory cells positive for CD36 - a membrane protein involved in FA uptake [52] - LA was capable of inducing an increase in intracellular $\mathrm{Ca}^{2+}$ levels, whereas in CD36-negative gustatory cells it was unable to affect intracellular $\mathrm{Ca}^{2+}$ [53]. On the other hand, LA - similarly to $\gamma$-LIN and to the $\Omega-9$ fatty acid EA- was able to lower total and cellular content of both CA, which can be a consequence of PNMT expression inhibition (Fig. 3. B-1) together with an increase in the function of enzymes involved in CA catabolism and/or a lower function of transporters involved in CA re-uptake.

Epidemiological and clinical studies have established an inverse relationship between the ingestion of $\Omega-3$ polyunsaturated FA (eg. EPA and DHA) and mortality associated with CDV disease (reviewed in [54]). In our study, EPA was the only FA that significantly decreased the expression of enzymes involved in CA synthesis (TH 
421 and PNMT) whereas DHA only affected the expression of PNMT. Curiously, the 422 decrease of mRNA levels induced by these FA was not associated with either a change 423 in the cellular content of CA or a change in their basal release. The maintenance of CA 424 cellular content could have been achieved primarily by decreasing CA release and/or by 425 maintaining $\mathrm{TH}$ and PNMT function (for instance, through an increase of their 426 activities) (Fig. 3. D-1). In addition, other mechanisms, such as a decrease in CA 427 catabolism (through an inhibition of monoamine oxidase and/or catechol - $O$ 428 methyltransferase) (Fig. 3. D-2), and/or an increase in their cellular reuptake (Fig. 3. D429 3) may have been also involved in those effects. Both EPA and DHA decreased CA 430 release induced by $\mathrm{KCl}$. This effect could be associated with an impairment of $\mathrm{Ca}^{2+}$ 431 disposal, since several studies have shown that $\Omega$-3 FA are able to affect intracellular $432 \mathrm{Ca}^{2+}$ levels through several mechanisms $[55,56]$.

433 An important point to discuss is the fact that, in order to clarify the intracellular 434 mechanisms underlying the effects of the above FA upon CA handling further studies 435 are needed. Since $\mathrm{Ca}^{2+}$ is a good candidate for the action of these molecules, its 436 intracellular levels should be measured. In addition, the activity and expression of 437 vesicular and membrane transporters and enzymes responsible for CA metabolism (eg. 438 catechol- $O$-methyltransferase and monoamine oxidase) should also be analyzed in the 439 future. Furthermore, in relation to TH and PNMT we only studied their mRNA levels 440 and it would be relevant to also measure their protein levels and activities.

441 Our results showing that unsaturated FA had an impact on CA handling suggest 442 that these amines might indeed constitute mediating factors in the well-documented 443 relationship between unsaturated FA, metabolic syndrome and CDV disease.

444 The major conclusion of this work is that the unsaturated fatty acids tested were 445 able to significantly modify CA handling by chromaffin cells, in good agreement with 446 previously described FA effects on neurosecretion [16-19]. Given the crucial role of CA 447 in the regulation of metabolic CDV homeostasis, among other physiological effects, 448 these results deserve attention and future development, namely in what concerns the 449 mechanisms involved and correlative effects in vivo. Thus, after this preliminary in vitro 450 study, we plan to expand our studies to determine if the fatty acids with the most 451 relevant effects, namely elaidic and $\Omega-3$ FA, might also have similar actions upon 452 catecholamine handling in animal models. 
456 This work was supported by U.Porto/Santander Totta (IJUP: 179/2010). A.L.T.

457 is a recipient of a doctoral degree grant from FCT (SFRH/BD/47381/2008). The authors 458 thank to Ricardo Escada for technical assistance with HPLC.

459

460 
463 [1] Misra A, Khurana L. Obesity and the Metabolic Syndrome in Developing Countries. 464 J Clin Endocrinol Metab 2008;93:s9-s30.

465 [2] Ribeiro L, Martel F, Azevedo I. Effect of somatostatin on the release of adrenaline 466 and noradrenaline from bovine adrenal chromaffin cells. In: Borges R, Gandía L, 467 editors. Cell Biology of the chromaffin cell. Instituto Teófilo Hernando 2004. p. 1-4.

468 [3] Ribeiro L, Martel F, Azevedo I. The release of 3H-1-methyl-4-phenylpyridinium 469 from bovine adrenal chromaffin cells is modulated by somatostatin. Regul Pept $470 \quad 2006 ; 137: 107-13$.

471 [4] Christensen NJ, Schultz-Larsen K. Resting venous plasma adrenalin in 70-year-old 472 men correlated positively to survival in a population study: the significance of the 473 physical working capacity. J Intern Med 1994;235:229-32.

474 [5] Reims HM, Sevre K, Fossum E, Mellem H, Eide IK, Kjeldsen SE. Adrenaline 475 during mental stress in relation to fitness, metabolic risk factors and cardiovascular 476 responses in young men. Blood Press 2005;14:217-26.

477 [6] Lafontan M, Langin D. Lipolysis and lipid mobilization in human adipose tissue. 478 Prog Lipid Res 2009;48:275-97.

479 [7] Migrenne S, Magnan C, Cruciani-Guglielmacci C. Fatty acid sensing and nervous 480 control of energy homeostasis. Diabetes Metab 2007;33:177-82

481 [8] Mozaffarian D, Katan MB, Ascherio A, Stampfer MJ, Willett WC. Trans fatty acids 482 and cardiovascular disease. N Engl J Med 2006;354:1601-13.

483 [9] Brouwer IA, Wanders AJ, Katan MB. Effect of animal and industrial trans fatty 484 acids on HDL and LDL cholesterol levels in humans - A quantitative review. PLoS 485 ONE 2010;5:e9434.

486 [10] Simopoulos AP. Omega-3 fatty acids in health and disease and in growth and 487 development. Am J Clin Nutr 1991;54:438-63.

488 [11] Russo GL. Dietary n-6 and n-3 polyunsaturated fatty acids: from biochemistry to 489 clinical implications in cardiovascular prevention. Biochem Pharmacol 2009;77:937-46. 490 [12] Olza J, Mesa MD, Aguilera CM, Moreno-Torres R, Jiménez Á, Pérez de la Cruz A, 491 et al. Influence of an eicosapentaenoic and docosahexaenoic acid-enriched enteral 492 nutrition formula on plasma fatty acid composition and biomarkers of insulin resistance 493 in the elderly. Clin Nutr 2010;29:31-7. 
494 [13] Poudyal H, Panchal SK, Diwan V, Brown L. Omega-3 fatty acids and metabolic

495 496 497 498

499

500

501

502

503

504

505

506

507

508

509

510

511

512

513

514

515

516

517

518

519

520

521

522

523

524

525

syndrome: Effects and emerging mechanisms of action. Prog Lipid Res 2011;50:372-87. [14] Poudyal H, Panchal SK, Ward LC, Brown L. Effects of ALA, EPA and DHA in high-carbohydrate, high-fat diet-induced metabolic syndrome in rats. J Nutr Biochem 2013;24:1041-52.

[15] Mozaffarian D, Clarke R. Quantitative effects on cardiovascular risk factors and coronary heart disease risk of replacing partially hydrogenated vegetable oils with other fats and oils. Eur J Clin Nutr 2009;63:S22-S33.

[16] Lesa GM, Palfreyman M, Hall DH, Clandinin MT, Rudolph C, Jorgensen EM, et al. Long chain polyunsaturated fatty acids are required for efficient neurotransmission in C. elegans. J Cell Sci 2003;116:4965-75.

[17] Rigoni M, Caccin P, Gschmeissner S, Koster G, Postle AD, Rossetto O, et al. Equivalent Effects of Snake PLA2 Neurotoxins and Lysophospholipid-Fatty Acid Mixtures. Science 2005;310:1678-80.

[18] Darios F, Davletov B. Omega-3 and omega-6 fatty acids stimulate cell membrane expansion by acting on syntaxin 3. Nature 2006;440:813-7.

[19] Ogawa N, Ito M, Yamaguchi H, Shiuchi T, Okamoto S, Wakitani K, et al. Intestinal fatty acid infusion modulates food preference as well as calorie intake via the vagal nerve and midbrain-hypothalamic neural pathways in rats. Metabolism 2012;61:1312-20.

[20] Ribeiro L, Martel F, Azevedo I. Catecholamine (CA) content and release from adrenal chromaffin cells is differentially influenced by fatty acids. FASEB $\mathbf{J}$ 2008;22:1195.

[21] Darios F, Ruipérez V, López I, Villanueva J, Gutierrez LM, Davletov B. $\alpha$-Synuclein sequesters arachidonic acid to modulate SNARE-mediated exocytosis. EMBO Rep 2010;11:528-33.

[22] Livett BG. Adrenal medullary chromaffin cells in vitro. Phys Rev 1984;64:110361.

[23] Livett BG, Boksa P, Dean DM, Mizobe F, Lindenbaum MH. Use of isolated chromaffin cells to study basic release mechanisms. J Auton Nerv Syst 1983;7:59-86.

[24] Almeida T, Cunha RA, Ribeiro JA. Facilitation by arachidonic acid of acetylcholine release from the rat hippocampus. Brain Res 1999;826:104-11. 
526 [25] Soares-da-Silva P, Pestana M, Vieira-Coelho MA, Fernandes MH, Albino-Teixeira

527 A. Assessment of renal dopaminergic system activity in the nitric oxide-deprived 528 hypertensive rat model. Br J Pharmacol 1995;114:1403-13.

529 [26] Mosmann T. Rapid colorimetric assay for cellular growth and survival: Application 530 to proliferation and cytotoxicity assays. J Immunol Methods 1983;65:55-63.

531 [27] Bradford M. A Rapid and sensitive method for the quantitation of microgram 532 quantities of protein utilizing the principle of protein-dye binding. Anal Biochem $5331976 ; 72: 248-54$.

534 [28] Livak KJ, Schmittgen TD. Analysis of relative gene expression data using real-time 535 quantitative PCR and the $2-\Delta \Delta C T$ method. Methods 2001;25:402-8.

536 [29] Krogager TP, Nielsen LV, Bak S, Young C, Ferreri C, Jensen ON, et al. 537 Identification of a potential biomarker panel for the intake of the common dietary trans 538 fat elaidic acid (trans $\Delta$ 9-C18:1). J Proteomics 2012;75:2685-96.

539 [30] Jala RCR, Guo Z, Bjerring T, Xu X. Interference effects from coexisting fatty acids 540 on elaidic acid separation by fractionating crystallization: A model study. Eur J Lipid $541 \quad$ Sci Technol 2010;112:1375-83.

542 [31] Du Z-Y, Degrace P, Gresti J, Loreau O, Clouet P. Dissimilar properties of vaccenic 543 versus elaidic acid in $\beta$-oxidation activities and gene regulation in rat liver cells. Lipids 544 2010;45:581-91.

545 [32] Gebauer SK, Chardigny J-M, Jakobsen MU, Lamarche B, Lock AL, Proctor SD, et 546 al. Effects of ruminant trans fatty acids on cardiovascular disease and cancer: A 547 comprehensive review of epidemiological, clinical, and mechanistic studies. Adv Nutr $548 \quad 2011 ; 2: 332-54$.

549 [33] Zelber-Sagi S, Ratziu V, Oren R. Nutrition and physical activity in NAFLD: An 550 overview of the epidemiological evidence. World J Gastroenterol 2011;17:3377-89.

551 [34] Bansal G, WeiBiao Z, TingWei T, FungLeng N, HuiLing L. Analysis of trans fatty 552 acids in deep frying oils by three different approaches. Food Chem 2009;116:535-41.

553 [35] Koda Y, Wada A, Yanagihara N, Uezono Y, Izumi F. cis-Unsaturated fatty acids 554 stimulate catecholamine secretion, tyrosine hydroxylase and protein kinase $\mathrm{C}$ in adrenal 555 medullary cells. Neuroscience 1989;29:495-502.

556 [36] Murayama T, Kajiyama Y, Takahashi A, Nomura Y. Modes of inhibitory action of 557 43-phorbol 12-myristate 13-acetate in thrombin-stimulated arachidonic acid release in 558 intact and permeabilized platelets. Arch Biochem Biophys 1990;276:146-52. 
559 [37] Vitale N, Thiersé D, Bader M-F. Melittin promotes exocytosis in neuroendocrine 560 cells through the activation of phospholipase A2. Regul Pept 2010;165:111-6.

561 [38] Vitale N, Thiersé D, Aunis D, Bader M-F. Exocytosis in chromaffin cells: evidence 562 for a MgATP-independent step that requires a pertussis toxin-sensitive GTP-binding 563 protein. Biochem J 1994;300:217-27.

564 [39] Mochizuki-Oda N, Negishi M, Mori K, Ito S. Arachidonic acid activates cation 565 channels in bovine adrenal chromaffin cells. J Neurochem 1993;61:1882-90.

566 [40] Soldati L, Lombardi C, Adamo D, Terranegra A, Bianchin C, Bianchi G, et al. 567 Arachidonic acid increases intracellular calcium in erythrocytes. Biochem Biophys Res 568 Commun 2002;293:974-8.

569 [41] Ramwell PW, Shaw JE, Douglas WW, Poisner AM. Efflux of prostaglandin from 570 adrenal glands stimulated with acetylcholine. Nature 1966;210:273-4.

571 [42] Yung HS, Chow KBS, Lai KH, Wise H. Gi-coupled prostanoid receptors are the 572 likely targets for COX-1-generated prostanoids in rat pheochromocytoma (PC12) cells. 573 Prostaglandins Leukot Essent Fatty Acids 2009;81:65-71.

574 [43] DeGeorge J, Walenga R, Carbonetto S. Nerve growth factor rapidly stimulates 575 arachidonate metabolism in PC12 cells: potential involvement in nerve fiber growth. J 576 Neurosci Res 1988;21:323-32.

577 [44] Namba T, Sugimoto Y, Negishi M, Irie A, Ushikubi F, Kakizuka A, et al. 578 Alternative splicing of C-terminal tail of prostaglandin E receptor subtype EP3 579 determines G-protein specificity. Nature 1993;365:166-70.

580 [45] Shibuya I, Tanaka K, Uezono Y, Ueta Y, Toyohira Y, Yanagihara N, et al. 581 Prostaglandin E2 Induces Ca2+ Release from Ryanodine/Caffeine-Sensitive Stores in 582 Bovine Adrenal Medullary Cells via EP1-Like Receptors. J Neurochem 1999;73:216758374

584 [46] Breyer MD, Jacobson HR, Davis LS, Breyer RM. In situ hybridization and 585 localization of mRNA for the rabbit prostaglandin EP3 receptor. Kidney Int 586 1993;44:1372-8.

587 [47] Currie KPM, Zhou Z, Fox AP. Evidence for paracrine signaling between 588 macrophages and bovine adrenal chromaffin cell $\mathrm{Ca}^{2+}$ channels. J Neurophysiol $589 \quad 2000 ; 83: 280-7$.

590 [48] Jewell ML, Breyer RM, Currie KPM. Regulation of calcium channels and 591 exocytosis in mouse adrenal chromaffin cells by prostaglandin EP3 receptors. Mol 592 Pharmacol 2011;79:987-96. 
593 [49] Cantrill RC, Patterson PP, Ells GW, Horrobin DF. Exogenous gamma-linolenic 594 acid alters hormone stimulated cyclic AMP levels in U937 cells. Cancer Letters 595 1996;100:17-21.

596 [50] Carrillo C, Cavia MM, Alonso-Torre SR. Oleic acid versus linoleic and $\alpha$-linolenic 597 acid. Different effects on $\mathrm{Ca}^{2+}$ signaling in rat thymocytes. Cell Physiol Biochem $598 \quad 2011 ; 27: 373-80$.

599 [51] Feng D-D, Zhao Y-F, Luo Z-Q, Keating DJ, Chen C. Linoleic acid induces $\mathrm{Ca}^{2+}$ 600 induced inactivation of voltage-dependent $\mathrm{Ca}^{2+}$ currents in rat pancreatic $\beta$-cells. $\mathrm{J}$ 601 Endocrinol 2008;196:377-84.

602 [52] Coburn C, Hajri T, Ibrahimi A, Abumrad N. Role of CD36 in membrane transport 603 and utilization of long-chain fatty acids by different tissues. J Mol Neurosci $6042001 ; 16: 117-21$.

605 [53] El-Yassimi A, Hichami A, Besnard P, Khan NA. Linoleic acid induces calcium 606 signaling, Src kinase phosphorylation, and neurotransmitter release in mouse CD36607 positive gustatory cells. J Biol Chem 2008;283:12949-59.

608 [54] Jump DB, Depner CM, Tripathy S. Omega-3 fatty acid supplementation and 609 cardiovascular disease. J Lipid Res 2012;53:2525-45.

610 [55] Gorjão R, Azevedo-Martins AK, Rodrigues HG, Abdulkader F, Arcisio-Miranda 611 M, Procopio J, et al. Comparative effects of DHA and EPA on cell function. Pharmacol 612 Ther 2009;122:56-64.

613 [56] Siddiqui RA, Harvey KA, Zaloga GP. Modulation of enzymatic activities by n-3 614 polyunsaturated fatty acids to support cardiovascular health. J Nutr Biochem $615 \quad 2008 ; 19: 417-37$.

616

617

618 
619 Tables caption

620

621 Table 1. Evaluation of total content, cellular content, basal release and $\mathrm{KCl}$-stimulated 622 release of noradrenaline after chronic treatment with fatty acids.

623

624 Table 2. Evaluation of total content, cellular content, basal release and $\mathrm{KCl}$-stimulated 625 release of adrenaline after chronic treatment with fatty acids.

626 


\section{Figures caption}

628

629 Figure 1. mRNA levels of tyrosine hydroxylase and phenylethanolamine N-

630 methyltransferase after chronic treatment with fatty acids. Comparison of mRNA levels

631 of tyrosine hydroxylase (TH) (A) and phenylethanolamine N-methyltransferase

632 (PNMT) (B) in control conditions and after chronic treatment with elaidic acid (EA), $\gamma$ -

633 linolenic acid ( $\gamma$-LIN), eicosapentaenoic acid (EPA), linoleic acid (LA) and

634 docosahexaenoic acid (DHA) at $100 \mu \mathrm{M}$ by quantitative real-time PCR, using

635 glyceraldehyde-3-phosphate dehydrogenase (GAPDH) as housekeeping gene ( $\mathrm{n}=4$ for

636 each group). ${ }^{*} p<0.05$, compared with control (ethanol).

637

638 Figure 2. mRNA levels of tyrosine hydroxylase and phenylethanolamine N-

639 methyltransferase after chronic treatment with oleic acid. Comparison of mRNA levels

640 of tyrosine hydroxylase (TH) (A) and phenylethanolamine N-methyltransferase

641 (PNMT) (B) in control conditions and after chronic treatment with oleic acid (OA) at

$642100 \mu \mathrm{M}$ by quantitative real-time PCR, using glyceraldehyde-3-phosphate

643 dehydrogenase (GAPDH) as housekeeping gene $(\mathrm{n}=4)$. * $p<0.05$, compared with

644 control (DMSO).

645

646 Figure 3. Putative intracellular mechanisms affected by chronic treatment with fatty

647 acids. Intracellular mechanisms affected by chronic treatment ( 24 hours) with either

648 elaidic and $\gamma$-linolenic acids (A), linoleic acid (B), arachidonic acid (C) or

649 eicosapentaenoic and docosahexaenoic acids (D) on catecholamine handling by bovine

650 chromaffin cells. Open circles: function increment; black cross: function impairment;

651 TH: tyrosine hydroxylase; AAAD: Aromatic L-amino acid decarboxylase; $\mathrm{D} \beta \mathrm{H}$ :

652 dopamine $\beta$-Hydroxylase; PNMT: phenylethanolamine N-methyltransferase; MAO:

653 monoamine oxidase; COMT: catechol $-O$ - methyltransferase; VMAT: vesicular

654 monoamine transporter; NET: noradrenaline transporter; NA: noradrenaline; AD:

655 adrenaline.

656 
Table 1. Evaluation of total content, cellular content, basal release and KCl-stimulated release of noradrenaline after chronic treatment with fatty acids.

\begin{tabular}{|c|c|c|c|c|c|c|c|c|}
\hline \multicolumn{9}{|c|}{ Noradrenaline } \\
\hline \multirow{2}{*}{ Parameters } & \multirow{2}{*}{ Groups } & \multicolumn{7}{|c|}{ Fatty acids } \\
\hline & & EPA & DHA & $\gamma$-LIN & LA & AA & OA & EA \\
\hline \multirow{3}{*}{ Total Content } & Control & $1541.03(1304.92-1733.97)$ & $1541.03(1304.92-1733.97)$ & $522.86(469.64-644.16)$ & $522.86(469.64-644.16)$ & $209.57(116.99-424.13)$ & $209.64(179.38$ - 322. 22$)$ & $405.67(323.02-461.43)$ \\
\hline & $50 \mu \mathrm{M}$ & 2055.78 (1029.48 - 2766.93) & $1303.39(885.81-1447.75)$ * & $488.49(245.29-544.63)$ & $406.74(316.37$ - 421.72) * & $180.87(169.41$ - 192.99) & $214.05(198.06-235.32)$ & $285.25(207.37-325.26) *$ \\
\hline & $100 \mu \mathrm{M}$ & $929.90(659.41$ - 2386114.37) & $1183.82(533.52-1336.95) *$ & $404.93(213.37-451.81) *$ & $114.65(102.74-164.39) *$ & $184.93(148.38$ - 212.64) & $202.43(200.79-241.54)$ & $205.72(129.39-239.19)$ * \\
\hline \multirow{3}{*}{ Cellular Content } & Control & $452.93(288.10$ - 1397.12) & $452.93(288.10$ - 1397.11) & $279.07(230.38$ - 330.04) & $279.07(230.38$ - 330.04) & $1799.37(89.83-275.42)$ & 182.91 (136.38 - 221.94) & $137.95(127.39-148.39)$ \\
\hline & $50 \mu \mathrm{M}$ & $1313.76(409.53-2588.07)$ & $828.03(366.27$ - 1296.59) & $237.59(91.62-296.65)$ & $205.25(165.83-217.74) *$ & $144.76(115.18-172.01)$ & $165.813(148.99-202.44)$ & $101.11(49.23-137.32)$ \\
\hline & $100 \mu \mathrm{M}$ & $359.45(215.79$ - 2233.76) & $1054.66(156.56-1153.47)$ & $186.54(66.68-233.73) *$ & $32.90(28.07-62.14) *$ & $158.68(90.12-173.59)$ & $170.66(140.05-205.39)$ & $70.58(32.31-86.90)$ * \\
\hline \multirow{3}{*}{ Basal Release } & Control & $0.97(0.57-1.31)$ & $0.97(0.57-1.31)$ & $0.96(0.68-1.21)$ & $0.96(0.68-1.21)$ & $0.90(0.80-1.29)$ & $1.00(0.73-1.17)$ & $1.05(0.68-1.27)$ \\
\hline & $50 \mu \mathrm{M}$ & $0.89(0.43-1.54)$ & $0.68(0.51-1.05)$ & $0.66(0.56-0.87)$ & $0.79(0.75-0.85)$ & $1.06(0.97-1.15)$ & $0.93(0.77-1.24)$ & $0.52(0.35-0.59) *$ \\
\hline & $100 \mu \mathrm{M}$ & $0.82(0.29-1.03)$ & $0.56(0.44-0.76)$ & $0.8545(0.72-1.22)$ & $0.51(0.45-0.54) *$ & $1.43(1.02-1.89) *$ & $0.88(0.71-1.37)$ & $0.44(0.42-0.49) *$ \\
\hline \multirow{3}{*}{ KCl-stimulated release } & Control & $2.57(2.22-3.33)$ & $2.58(2.22-3.33)$ & $1.67(1.47-1.79)$ & $1.67(1.47-1.80)$ & $1.02(0.94-1.34)$ & $1.17(0.88-1.59)$ & $1.58(1.50-1.78)$ \\
\hline & $50 \mu \mathrm{M}$ & $0.38(0.26-0.64) *$ & $0.70(0.63-0.92) *$ & $1.22(1.10-1.44) *$ & $1.09(0.85-1.44)$ & $0.74(0.54-0.84) *$ & $1.00(0.69-1.08)$ & $1.08(0.97-1.18) *$ \\
\hline & $100 \mu \mathrm{M}$ & $0.71(0.63-0.91) *$ & $0.64(0.46-0.78) *$ & $0.86(0.78-0.98) *$ & $1.79(1.67-2.17)$ & $0.59(0.30-0.85)$ * & $0.76(0.60-0.89) *$ & $1.05(0.83-1.14)$ * \\
\hline
\end{tabular}

Results are presented as nmol /mg protein median (p25-p75).

* $p<0.05$, compared with control group. EPA: eicosapentaenoic acid; DHA: docosahexaenoic acid; OA: oleic acid; EA: elaidic acid; $\gamma$-LIN: $\gamma$-linolenic acid;

LA: linoleic acid; AA:arachidonic acid. 
Table 2. Evaluation of total content, cellular content, basal release and KCl-stimulated release of adrenaline after chronic treatment with fatty acids.

Adrenaline

\begin{tabular}{|c|c|c|c|c|c|c|c|c|}
\hline \multirow{2}{*}{ Parameters } & \multirow{2}{*}{ Groups } & \multicolumn{7}{|c|}{ Fatty acids } \\
\hline & & EPA & DHA & $\gamma$-LIN & LA & AA & OA & EA \\
\hline \multirow{3}{*}{ Total Content } & Control & $8985.59(6834.22$ - 10642.50) & $8985.59(6834.22$ - 10642.50) & $1033.42(950.86-1304.29)$ & $1033.42(950.86-1304.29)$ & $420.33(267.32-673.32)$ & $457.94(371.53$ - 526.28) & $1073.92(1019.43-1144.13)$ \\
\hline & $50 \mu \mathrm{M}$ & $9986.71(9247.85-11002.50)$ & 8094.28 (5712.06- 8665.94) * & $1003.29(515.97-1135.75)$ & $776.39(585.87-819.48) *$ & $346.27(297.18-385.52)$ & $407.81(368.53-485.09)$ & $999.57(795.50$ - 1163.65) \\
\hline & $100 \mu \mathrm{M}$ & $8499.87(7127.78-9929.24)$ & $5594.61(5252.21-6205.32) *$ & $824.81(420.75-947.15) *$ & $220.76(195.78-334.53) *$ & $377.57(273.34-422.33)$ & $392.23(356.65$ - 493.63) & $819.99(513.35-889.27) *$ \\
\hline \multirow{3}{*}{ Cellular Content } & Control & $3839.46(2460.60$ - 5804.53) & $3839.46(2460.60$ - 5804.53) & $618.98(549.81$ - 775.71) & $618.98(549.81$ - 775.71$)$ & $355.13(197.80$ - 493.88) & $397.17(291.75-426.20)$ & $499.60(473.30$ - 544.06) \\
\hline & $50 \mu \mathrm{M}$ & $6686.84(3342.07$ - 10455.66) & $4577.85(3305.44-5309.11)$ & $594.22(220.19-728.03)$ & $488.95(385.95-516.25) *$ & $285.90(224.74-344.17)$ & $329.70(299.25$ - 207.10) & $387.28(210.36-518.56)$ \\
\hline & $100 \mu \mathrm{M}$ & $2869.04(1752.05-9511.40)$ & $4517.29(1370.19-4908.64)$ & $450.70(158.90-580.28) *$ & $69.89(61.66-149.72) *$ & $318.74(189.93-349.51)$ & $335.96(288.79$ - 423.92) & $301.75(132.07-375.07)$ * \\
\hline \multirow{3}{*}{ Basal Release } & Control & $0.87(0.79-1.06)$ & $0.87(0.79-1.06)$ & $0.87(0.69-1.36)$ & $0.87(0.69-1.36)$ & $0.90(0.75-1.21)$ & $0.99(0.73-1.25)$ & $0.99(0.87-1.18)$ \\
\hline & $50 \mu \mathrm{M}$ & $0.90(0.84-1.37)$ & $0.87(0.78-1.06)$ & $0.65(0.56-0.88)$ & $0.78(0.70-0.86)$ & $1.15(1.06-1.33)$ & $1.01(0.80-1.23)$ & $0.68(0.60-0.89) *$ \\
\hline & $100 \mu \mathrm{M}$ & $0.86(0.72-1.11)$ & $0.83(0.68-0.91)$ & $1.02(0.88-1.61)$ & $0.53(0.40-0.59) *$ & $1.43(1.06-1.91) *$ & $0.90(0.73-1.30)$ & $0.83(0.74-0.89)$ \\
\hline \multirow{3}{*}{ KCl-stimulated release } & Control & $3.24(2.73-4.11)$ & $3.24(2.73-4.11)$ & $1.37(1.24-1.56)$ & $1.37(1.24-1.56)$ & $1.08(0.91-1.56)$ & $1.12(0.86-1.69)$ & $1.24(1.21-1.37)$ \\
\hline & $50 \mu \mathrm{M}$ & $0.36(0.32-0.72) *$ & $0.42(0.33-0.84) *$ & $1.27(1.01-1.42)$ & $1.12(0.93-1.45)$ & $0.72(0.62-0.83) *$ & $0.84(0.72-1.02)$ & $0.79(0.69-0.84) *$ \\
\hline & $100 \mu \mathrm{M}$ & $0.58(0.47-0.82) *$ & $0.46(0.34-0.52) *$ & $0.73(0.60-0.95) *$ & $1.99(1.78-2.47) *$ & $0.58(0.23-0.71) *$ & $0.65(0.55-1.12) *$ & $0.87(0.80-1.00) *$ \\
\hline
\end{tabular}

Results are presented as nmol/mg protein median (p25-p75).

$* p<0.05$, compared with control group. EPA: eicosapentaenoic acid; DHA: docosahexaenoic acid; OA: oleic acid; EA: elaidic acid; $\gamma$-LIN: $\gamma$-linolenic acid;

LA: linoleic acid; AA:arachidonic acid. 
Figure(s)

A

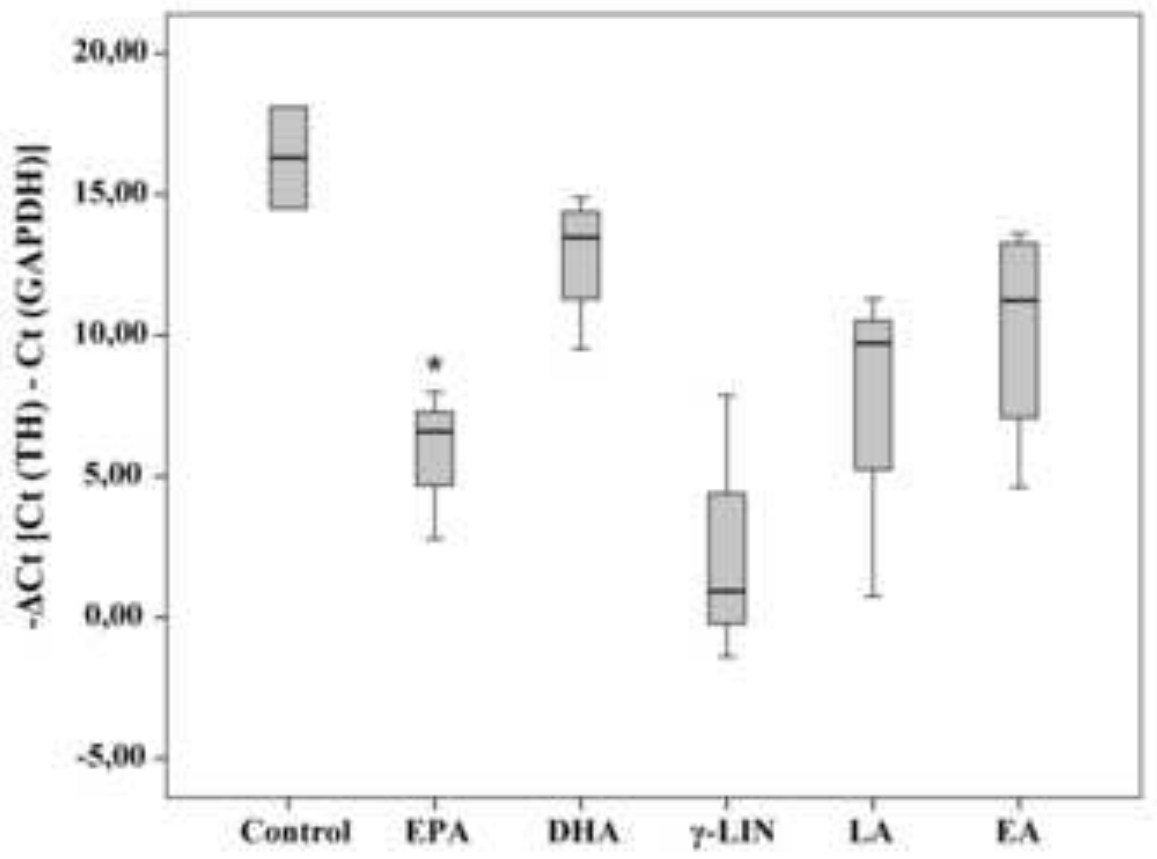

B

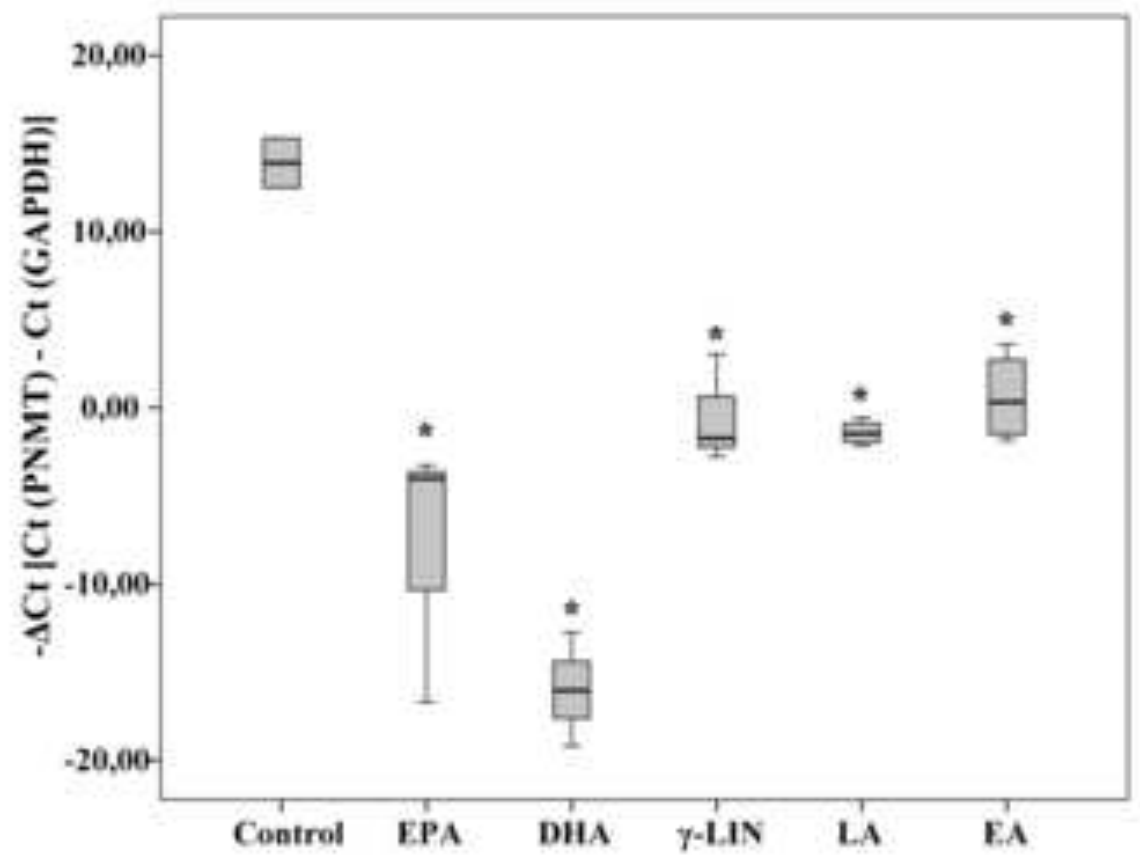



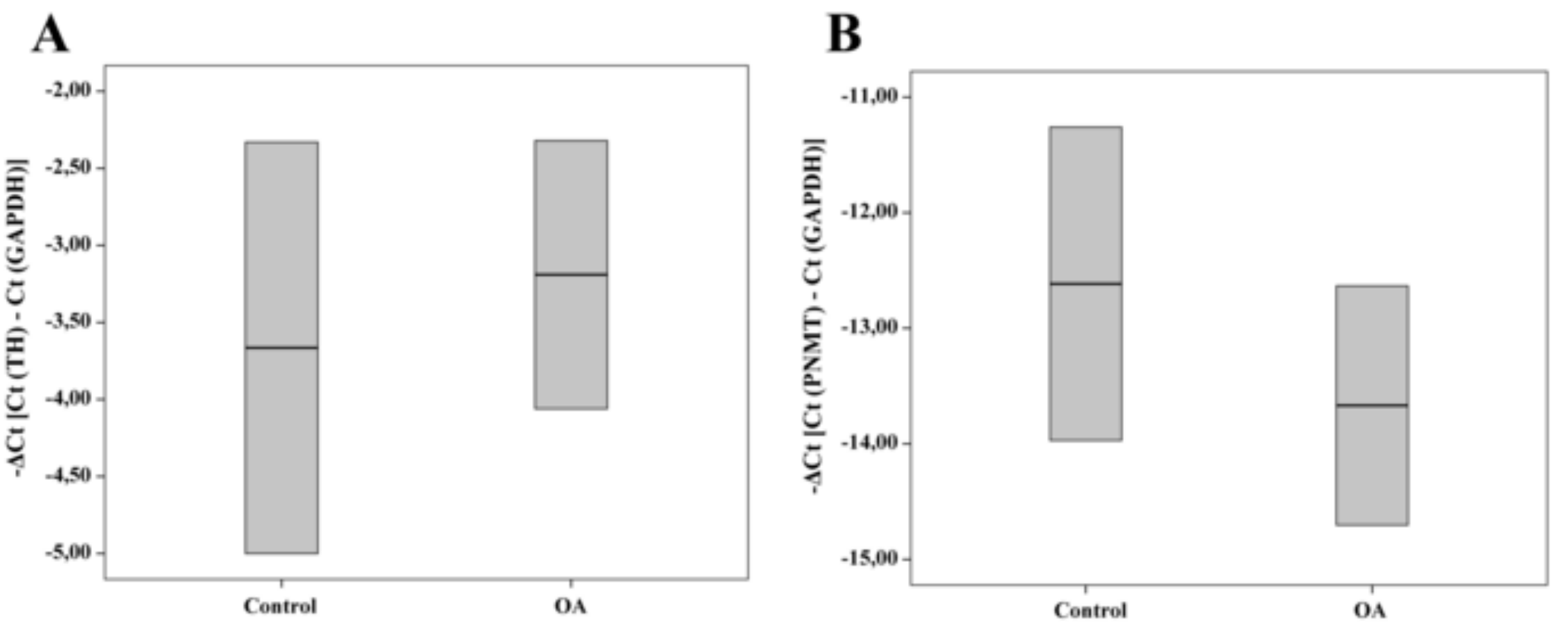
Figure 3

(F)

. .}

.

(

(

(

(

(

(2)

(

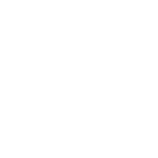

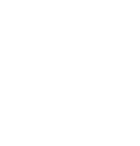

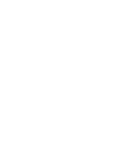

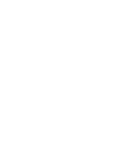

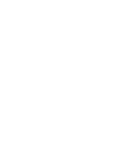

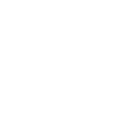

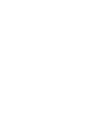

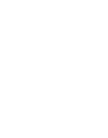

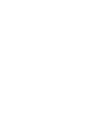

.

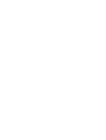

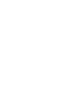

.

.

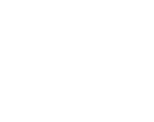

